diabetic patients to create a greater awareness of available treatments. Once identified, impotent men should be seen, with their partners if possible, in a relaxed sympathetic environment away from the busy diabetic clinic.

D E PRICE Consultant

School of Postgraduate Studies in Medical and Health Care, Morriston Hospital,

Swansea SA6 6NL

1 Price DE, O'Malley BP, James MA, Roshan M, Hearnshaw JR. Why are impotent diabetic men not being treated? Practical Diabetes 1991;8:10-1.

2 British Diabetic Association. What diabetic care to expect. Diabetic Med 1990;7:554.

3 Williams DRR, Home PD. A proposal for continuing audit of diabetes services. Diabetic Med 1991;9:759-64.

4 McCulloch DK, Young RJ, Prescott RJ, Campbell IW, Clarke BF. The natural history of impotence in diabetic men. Diabetologia 1984;26:437-40.
5 Fairburn CG, McCulloch DK, Wu FC. The effects of diabetes on male sexual function. Clinics in Endocrinology and Metabolism 1982;11:749-67.

6 McCulloch DK, Hosking DJ, Tobert A. A pragmatic approach to sexual dysfunction in diabetic men: psychosexual counselling. Diabetic Med 1986;3:485-9.

Wilson SK, Wahman GE, Lange JL. Eleven years' experience with the inflatable penile prosthesis. f Urol 1988;139:951-2.

8 Wiles PG. Erectile impotence in diabetic men: aetiology, investigation and management. Diabetic Med 1992:9:888-92.

9 Diagnostic and therapeutic technology assessment. Vasoactive intracavernous pharmacotherapy for impotence: intracavernous injection of prostaglandin E1. अAMA 1991;265:3321-3.

10 Alexander WD. The diabetes physician and an assessment and treatment programme for male erectile impotence. Diabetic Med 1990;7:540-3.

11 Hollander JB, Gonzalez J, Norman T. Patient satisfaction with pharmacologic erection program Urology 1992;39:439-41.

12 Turner LA, Althof SE, Levine SB, Bodner DR, Kursh ED, Resnick MI. Twelve month comparison of two treatments for erectile dysfunction: self injection versus external vacuum devices. Urology 1992;39:139-44.

13 Price DE, Cooksey G, Jehu D, Bentley S, Hearnshaw JR, Osborn DE. The management of impotence in diabetic men by vacuum tumescence therapy. Diabetic Med 1991;8:964-7.

14 Wiles PG. Successful non-invasive management of erectile impotence in diabetic men. $B M \mathcal{F}$ 1988;296:161-2.

15 Ryder REJ, Robinson A, Anderson J, Parnell L, Ward JD. Intracorporeal papaverine therapy versus vacuum constriction therapy (Erecaid) in the treatment of diabetic impotence [abstract]. Diabetic Med 1992;9(suppl 1):33A.

\title{
Hepatitis B vaccination: protection for how long and against what?
}

\author{
Booster injections are not indicated
}

The purpose of vaccination (used here to mean giving a vaccine) is to prevent disease, but some people would also like to prevent infection. The distinction between infection and disease is not trivial in the case of hepatitis $B$ vaccination. Infection with the virus results in the appearance of core antibody in the serum, and in most people this antibody persists for decades. In addition, those who become carriers of the virus will persistently test positive for surface antigen, and those who become immune will test positive for surface antibody.

Immunisation (used to imply a vaccination that results in a protective immune response) with hepatitis $B$ vaccine results in seropositivity for surface antibody alone. Thus if previously immunised people test positive for core antibody then this indicates infection; if this is associated with persistent surface antigenaemia then the person is at high risk of chronic hepatitis, cirrhosis, and hepatocellular carcinoma. In addition, becoming positive for core antibody may coincide with acute clinical hepatitis.

Immunisation with hepatitis $B$ vaccine is considered to have occurred if concentrations of surface antibody greater than $10 \mathrm{IU} / \mathrm{h}$ develop. Non-response to vaccination is associated with increasing age, male sex, obesity, vaccination in the buttock, and immunosuppression-for example, due to HIV infection and renal dialysis. In these situations repeat doses and increased dosage can result in immunisation. Decay of the putative protective antibody occurs so predictably that when a person's antibody concentration will fall below 10 IU/1 can be predicted from the peak antibody response after immunisation. ${ }^{1}$ For example, a peak antibody concentration of $100 \mathrm{IU} / \mathrm{l}$ can be expected to fall below 10 in about five years, which has been the basis for scheduling booster doses of vaccine.

In this issue Oates et al report a study of hepatitis B vaccination of medical students, which suggests that many students thought that vaccination implied lifelong immunity (p 301). ${ }^{2}$ Were they right or wrong? Is antibody concentration a true marker of protection and does disappearance of antibody equate with becoming susceptible again? More importantly, is this susceptibility to infection or to disease? The answers to these questions lie in long term follow up studies of immunised populations who continue to have a high risk of exposure and in whom surveillance of serological events and acute hepatitis is possible. There are seven such published studies.

Two trials of vaccination to interrupt perinatal transmission showed a vaccine efficacy at 1 year of age of $88 \%$. From these trials Stevens et al followed up for between four and nine years 104 of 235 children who were uninfected at 18 months of age. ${ }^{3}$ None of these children became a carrier of the virus or had a history of acute hepatitis, although $7 \%$ became core antibody positive.

Globally, infection with hepatitis B virus most commonly occurs during childhood. Four studies have examined the duration of protection conferred by vaccination of infants in populations at high risk of childhood infection. In Senegal follow up of children to the age of 7 found that only four out of 135 children were surface antigen positive; whether they were carriers is not known. ${ }^{4}$ In two studies in the Gambia follow up to age 5 has shown frequent infection but no evidence of acute hepatitis. ${ }^{56}$ Although carriers were found in these studies, none were in children with a documented antibody response to the vaccine. In Alaska a study of 1693 children found $100 \%$ protection against carriage of the virus five years after vaccination. ${ }^{7}$ Only four children had evidence of infection, of whom none had associated acute hepatitis.

Two large scale randomised trials in adult homosexual men provide long term information. The first reported on 1100 men at high risk of hepatitis $B$ infection who were randomised to placebo or vaccine derived from plasma. The protective efficacy against infection at 18 months was $92 \%$. Subgroups of those who had been vaccinated in this trial were followed up for longer periods. A subsequent report on 127 of these men who tested negative for HIV-1 showed that none tested positive for hepatitis B surface antigen, although $4 \%$ tested positive for core antibody. ${ }^{8}$ None had suffered clinical acute hepatitis $B$.

In the second trial, the Centers for Disease Control multicentre trial of hepatitis $B$ vaccination, those in the placebo group who remained susceptible at the time of the first analysis were vaccinated. A group of these and those in the vaccinated group are still being followed up. ${ }^{9} A$ total of 733 men were followed up after vaccination was completed; $15 \%$ of those with detectable antibody lost it within this time. Hepatitis B infection occurred in 55 men. In eight this was associated with increased liver enzyme activity and the 
appearance of hepatitis B surface antigen. Only two of these men had been successfully immunised; the only two men who had become carriers of the hepatitis B virus were nonresponders to the vaccine.

These data must be interpreted in the context of the known relation between disease and age at infection in unimmunised people. Infection in childhood carries the highest risk of persistent viral carriage but a small risk of acute hepatitis. In contrast, adult infection causes acute hepatitis in $30-50 \%$ of people but leads to carriage in fewer than $10 \%$.

Successful immunisation will not result in persistent protective antibody levels and those exposed to infection may be infected, as shown by anticore seroconversion. This will rarely be associated with acute hepatitis. Despite the loss of antibody it seems that people are still protected against becoming carriers of the virus. Clearly, longer follow up of immunised people is needed to guide policy, but currently no reason exists for recommending booster vaccinations as a public health measure. The medical students who believed that vaccination implied lifelong protection may yet turn out to be right. Whether antibody responses after vaccination should be verified and subsequent decay documented, will depend on local resources and individual decisions by both the vaccinator and the person who has been vaccinated.

ANDREW J HALL

Senior lecturer in epidemiology

Communicable Disease Epidemiology Unit,

Department of Epidemiology and Population Sciences,

London School of Hygiene and Tropical Medicine,

London WC1E 7HT

1 Jilg W, Schmidt M, Deinhardt F, Zachoval R. Hepatitis B vaccination: how long does protection last? Lancet 1984;ii:458.

2 Oates BC, Sidebottom AJ, Maxwell SRJ. Efficacy of hepatitis B vaccination: knowledge among clinical medical students. BMf 1993;307:301.

3 Stevens CE, Toy PT, Taylor PE, Lee T, Yip H. Prospects for control of hepatitis B virus infection: implications of childhood vaccination and long-term protection. Pediatrics 1992;90:170-3.

Coursaget P, Yvonnet B, Chotard J, Sarr M, Vincelot P, N'Doye R, et al. Seven year study of hepatitis $B$ vaccine efficacy in infants from an endemic area (Senegal). Lancet 1986;ii:1143-5.

Whittle HC, Inskip H, Hall AJ, Mendy M, Downes R, Hoare S. Vaccination against hepatitis B and protection against chronic viral carriage in the Gambia. Lancet 1991;337:747-50.

Fortuin M, Chotard J, Jack AD, Maine NP, Mendy M, Hall AJ, et al. Efficacy of hepatitis B vaccine in the Gambian expanded programme on immunisation. Lancet 1993;341:1129-31.

7 Wainwright RB, McMahon BJ, Bulkow LR, Hall DB, Fitzgerald MA, Harpster AP, et al. Duration of immunogenicity and efficacy of hepatitis $\mathrm{B}$ vaccine in a Yupik Eskimo population. $尹$ AMM 1989;261:2362-6.

8 Taylor PE, Stevens CE. Persistence of antibody to hepatitis B surface antigen after vaccination with hepatitis B vaccine. In: Zuckerman AJ. Viral hepatitis and liver disease. New York: Alan Liss, 1988:995-7.

9 Hadler SC, Francis DP, Maynard JE, Thompson SE, Judson FN, Echenberg DF, et al. Long-term immunogenicity and efficacy of hepatitis B vaccine in homosexual men. $N$ Engl $尹$ Med 1986;315:209-14.

\section{Familial colorectal cancer}

\section{Better understanding of the genetics should mean better screening}

Colorectal cancer causes 25000 deaths each year in Britain, and yet if diagnosed at an early stage it is curable. Some patients with this cancer have a predisposition to the disease, which is inherited as an autosomal dominant. Relatives of these patients would be an ideal group in whom to undertake presymptomatic screening - which should be easier with the recent mapping of a gene to chromosome 2 which, it is claimed, may predispose to up to $15 \%$ of colorectal cancer. ${ }^{12}$

Clinicians are familiar with two relatively common inherited predispositions to cancer of the colon. Familial adenomatous polyposis accounts for about $1 \%$ of colorectal cancer and has a characteristic phenotype: patients with the disorder develop hundreds of adenomatous polyps in the colon during adolescence, and typically they develop colorectal cancer in the fourth decade. The gene responsible (known as APC) was mapped by family linkage analysis to chromosome 5 in 1987. ${ }^{34}$ Further polymorphic markers were then isolated and the gene identified and characterised in $1991 .^{5-8}$ These advances have made it possible to identify unaffected individuals, who do not need screening, and affected individuals in these families before they develop polyposis, when prophylactic colectomy may be offered.

Hereditary non-polyposis colon cancer causes between $5 \%$ and $15 \%$ of colorectal cancer. People with the disorder inherit (as an autosomal dominant) a predisposition to colon cancer and also to endometrial, stomach, biliopancreatic, and urinary tumours. In clinical practice affected families may be defined as those having at least three relatives in two generations with colorectal cancer, one of them having been diagnosed under age 50.9 The individuals with the abnormal gene do not develop numerous polyps but the few adenomatous polyps they do develop seem to undergo a rapid progression of tumourigenesis. ${ }^{10}$ In practice it has often been difficult to distinguish families with hereditary non-polyposis colon cancer-whose members should undergo surveillance colonoscopy - and those in which the clustering was due to chance. Guidance is now, however, becoming available from genetic research.

A group led by de la Chapelle and Vogelstein undertook family linkage analysis in two large, well characterised pedigrees with hereditary non-polyposis colon cancer. ${ }^{1}$ They were able to show tight linkage between a polymorphic DNA marker mapped to chromosome 2 and the development of tumours. The gene responsible has been provisionally named FCC (familial colorectal cancer). Fourteen other pedigrees with the disorder were then analysed for linkage to the same marker on chromosome 2: linkage was excluded in three families, but it was possible in about half the families. These findings may indicate that hereditary non-polyposis colon cancer is heterogeneous, with more than one gene being responsible; the alternative explanation is that some sporadic cases of colorectal cancer may have confounded the linkage analysis.

Several of the events that occur during the development of colorectal tumours have been characterised over the past few years. Tumourigenesis includes the activation of protooncogenes, such as k-ras, and the inactivation of tumour suppressor genes. The site of inactivation of these tumour suppressor genes can often be detected by the loss of genetic material in cancers. In colorectal cancer three tumour suppressor genes known to play a part are the APC gene on chromosome 5, the DCC (deleted in colorectal carcinoma) gene on chromosome 18, and the p53 gene on chromosome 17. Fearon and Vogelstein have proposed a model of sequence of events played by the recognised genes in colorectal tumourigenesis. ${ }^{11}$

No loss of genetic material on chromosome 2 has, however, been found in hereditary non-polyposis colon cancer tumours, and this indicates that the gene on chromosome 2 does not act as a typical tumour suppressor gene. ${ }^{1}$ Other genetic alterations found in hereditary non-polyposis colon cancer tumours were similar to those found in sporadic tumours. A 